\title{
Knowledge about Diabetes Mellitus and Self-Care Activities before and after an Educational Program: A Pilot Study
}

\author{
Nathália Martins de Moraes ${ }^{1}$ (D), Gislaine Faustino Pereira de Souza1 (i), \\ Fernando Inocêncio de Brito ${ }^{2}\left(\mathbb{B}\right.$, Maurício Eduardo Antonio Júnior ${ }^{2}$ (), \\ Alinson Eduardo Cipriano ${ }^{2}(\mathbb{0})$, Nilo Sérgio Vieira Costa ${ }^{3^{*}}(\mathbb{D})$, Tiago Marques de Rezende ${ }^{2^{*}}$ (D), $^{-}$ \\ Autran José da Silva Júnior ${ }^{2 *}(\mathbb{D})$, Lilian Cristiane Gomes ${ }^{1 *}$ (i)
}

\begin{abstract}
${ }^{1}$ Department of Nursing at the University Center of the Guaxupé Educational Foundation (UNIFEG), Guaxupé, Minas Gerais, Brazil ${ }^{2}$ Department of Physical Education at UNIFEG, Guaxupé, Minas Gerais, Brazil

${ }^{3}$ Department of Primary Health Care in Guaxupé City Hall, Guaxupé, Minas Gerais, Brazil

Email: nathalia_mmoraes@hotmail.com,gi.villa232@gmail.com, fernandogxp11@gmail.com, mauricioeduardo900@gmail.com, alinson.eduardo.3@gmail.com, nilosergioarquivos@yahoo.com.br, tiagomrezende@hotmail.com, autranjsilvajr@gmail.com, liliancristianegomes@yahoo.com.br
\end{abstract}

How to cite this paper: de Moraes, N.M., de Souza, G.F.P., de Brito, F.I., Antonio Jr, M.E., Cipriano, A.E., Costa, N.S.V., de Rezende, T.M., da Silva Jr., A.J. and Gomes, L.C. (2020) Knowledge about Diabetes Mellitus and Self-Care Activities before and after an Educational Program: A Pilot Study. Open Journal of Nursing, 10, 101-116. https://doi.org/10.4236/ojn.2020.102006

Received: January 3, 2020

Accepted: February 11, 2020

Published: February 14, 2020

Copyright $\odot 2020$ by author(s) and Scientific Research Publishing Inc. This work is licensed under the Creative Commons Attribution International License (CC BY 4.0).

http://creativecommons.org/licenses/by/4.0/ (c) (i) Open Access

\begin{abstract}
Background: Health education has proven to be an effective strategy to enable people with diabetes mellitus to manage this condition. However, few studies in Brazilian population samples have been conducted to evaluate the effects of educational programs on diabetes knowledge and self-care. Aim: To evaluate the knowledge about diabetes mellitus and the performance of self-care activities, before and after participation in an educational program. Methods: This is an intervention study, with a quantitative approach, in a single comparison group, for the analysis of "before and after" results related to an educational program focused on self-care and concurrent physical training. The study interventions consisted of 42 exercise sessions, as well as individual educational meetings, according to the needs of each participant and through nursing consultations, using educational material prepared from the literature. The sample was initially composed of 33 adults with diabetes mellitus, but 18 completed the study. For the assessment of knowledge and self-care activities, the revised Brazilian versions of the Diabetes Knowledge Scale and the Diabetes Self-Care Activity Questionnaire were used, respectively, in the two moments of the study, that is, prior to the first educational meeting and immediately before the first physical training session, and after the last educational meeting, which ran parallel to the 42nd physical training session, making a six-month interval between the two assessment moments
\end{abstract}

${ }^{\star}$ Member of the Study Group on Obesity, Diabetes and Hypertension (GEODIH). 
for each participant. Results: The analysis of knowledge about diabetes showed significant improvement after the educational program and, as for self-care, there was clinical improvement in all dimensions, but only the dimension "general diet" obtained statistically significant improvement. Conclusion: The educational program has been shown to be beneficial for improving knowledge and self-care of the disease, which reiterates the need to maintain interventions of this nature for people with diabetes mellitus.

\section{Keywords}

Diabetes Mellitus, Knowledge, Self-Care, Health Education, Nursing Care

\section{Introduction}

Diabetes mellitus (DM) has been noted for its high worldwide prevalence among chronic diseases that, when not properly treated, lead to complications [1]. A household survey conducted in Brazil in 2013 to estimate the prevalence of self-reported DM showed an estimated nine million people with the disease, and about 3.5 million of them are 65 years of age or older [2]. In South America, Brazil has the largest number of people with DM, with an estimated 16.8 million individuals in 2019 [3].

Poor glycemic control, added to the duration of the disease, is the main conditioning factor of morbidity related to DM. Thus, the focus of treatment is self-care, which aims to control glycemic levels to prevent possible complications and, consequently, promote quality of life and reduce mortality [1].

One of the most effective strategies for this control has been DM education. There is strong scientific evidence regarding the positive effects of DM education on disease control [4], even though there is not yet a "gold standard" model of education program [4] [5]. However, a literature review study on the education of people with chronic diseases points out that the first stage of an educational program is evaluative. This includes an assessment of cognition, prior knowledge and possible misconceptions as well as attitudes, motivation, skills and learning style. From this assessment, it is possible to identify the resources, barriers and educational needs of people [6].

Other individual characteristics that should be considered for the health education process for people with DM are age, education [5] [7], working and income conditions, length of illness, presence of comorbidities, and type of drug treatment [8]. In addition to all these characteristics, the educational process must be gradual, continuous and interactive [7]. It should include topics related to essential behaviors, such as: balanced diet, physical activity, blood glucose monitoring, proper use of medicines, foot and foot care, among others, which aim to solve problems, reduce risks and coping with the disease in a healthy way. The performance of self-care behaviors requires the person with DM to develop 
the skills necessary for decision making, making the individual take responsibility for their treatment. Therefore, its acceptance and the consolidation of its knowledge about the disease are fundamental [9] [10].

A cross-sectional study conducted among 82 Brazilian adults participating in a diabetes education program, which aimed to verify their knowledge and attitudes towards the disease, showed that participants had a good knowledge of diabetes and the strategies required for adherence self-care [11]. Other studies have also shown that educational programs in DM improve the knowledge and skills required for disease management and control [12] [13].

The role of the nurse is of great importance in educating the person with DM, by identifying individual needs and knowledge gaps, stimulating self-care actions, and developing priority care plans with the participation of the individual, proposing effective negotiations for better outcomes treatment [14]. Thus, identifying the knowledge that people have about their disease is a fundamental requirement for the planning and evaluation of educational interventions that may favor their effective control and the delay of its complications. Similarly, considering that the adoption of self-care behaviors is essential for maintaining the health status of people with DM, it is necessary to identify how people perform these behaviors and the effects provided by educational interventions. Therefore, the present study aims to evaluate the knowledge about the disease and the performance of self-care activities of people with diabetes mellitus, before and after participating in an educational program that included physical exercise sessions.

\section{Methods}

\subsection{Design and Ethical Aspects}

This is an intervention study with a quantitative approach, with a single comparison group for the analysis of "before and after" results [15], related to the educational program (EP) with people with DM, centered on self-care and concurrent physical training (Figure 1).

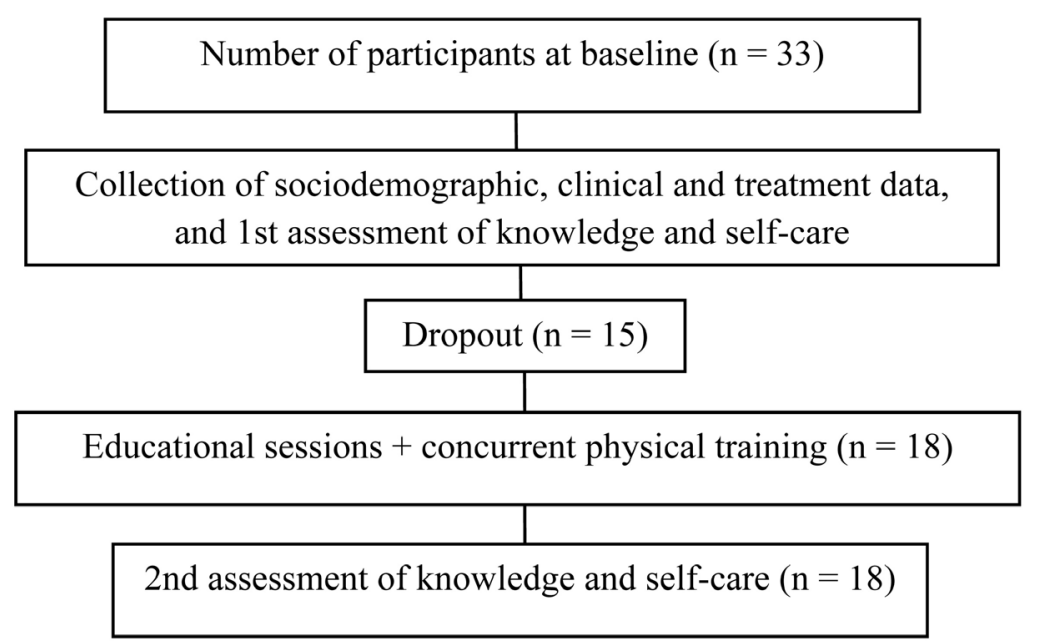

Figure 1. Study scheme. Source: Own (2019). 
This research was developed at the Center for Health and Physical Education Studies (CESEF) of the University Center of the Guaxupé Educational Foundation (UNIFEG), from October 2017 to April 2019, from the matrix project entitled "Evaluation of a educational program for people with type 2 diabetes mellitus, focusing on physical activity and foot care", approved by the UNIFEG Research Ethics Committee, protocol No. 2.029.352, of May 03, 2017. In previous studies [16] [17], coming from the same matrix project, the methodological aspects described below are detailed.

\subsection{Study Sample}

The base population consisted of people with a medical diagnosis of type $2 \mathrm{di}$ abetes mellitus (T2DM), regardless of the time of illness, not hospitalized and in outpatient follow-up. The invitation to study was carried out at public health services and by the local media. For sample selection, the following inclusion/exclusion criteria were considered:

- Inclusion criteria: persons of both sexes, at least 40 years old, sedentary or inactive, without advanced complications, whose drug treatment included the use of oral antidiabetic drugs (OADs) and/or insulin, and who were capable of maintain dialogue.

- Exclusion criteria: people with T2DM who had at least one of the following conditions were excluded: under hemodialysis treatment, amaurosis, presence of stroke/heart failure sequelae, previous amputations at any level of the lower limb, injury or ulcer process active in lower limbs, presence of any other disabling complication; use of wheelchair and/or stretcher; inability of verbal communication; and participants in a physical training program at another institution.

Thus, the sample was initially composed of 33 people with T2DM who met the inclusion criteria and voluntarily attended the study site. After being informed about the objectives and procedures of the study, including the need for a medical certificate for the practice of physical exercises, the Informed Consent Form (ICF) was provided for reading and signing. However, 15 people were abandoned due to lack of interest and/or time to attend educational meetings and/or physical training sessions, leaving the final sample of 18 participants who completed the study.

\subsection{Data Collection}

Data collection took place in a private room at the study site, in the form of an individual interview, with an average time of 40 minutes and performed at two moments of the study, i.e., before the first educational meeting and immediately before the first physical training session, (T0), and after the last educational meeting, which ran parallel to the 42nd physical training session, making a six-month interval (T6) between the two assessment moments for each participant. In the first phase of data collection, after signing the consent form, soci- 
odemographic, clinical and treatment data were collected to characterize the sample.

For the assessment of knowledge and self-care activities at both stages of the study, the Diabetes Knowledge Scale (DKN-A) [18] and the Diabetes Self-Care Activity Questionnaire (DSCAQ) [19] were used, both validated for Brazilian culture [20] [21]. The Brazilian version of the DKN-A is an instrument that assesses general knowledge about DM, consisting of 15 multiple choice items. For the correct answers, the value "one" must be assigned and for the incorrect answers, "zero". Items 1 through 12 have only one correct answer, and for items 13,14 , and 15 there are two correct ones. For these last items, the value "one" is assigned when both alternatives are correct and the value " 0.5 " if only one alternative is answered correctly. The sum total of the item scores determines the degree of knowledge, and it is considered good knowledge about the disease when the final score is equal to or higher than eight points [18]. In a previous study [13], the Brazilian version of DKN-A required adjustments to the wording of questions 1, 2, 7, 9, 14 and 15, because the instrument was translated and validated in another Brazilian region, with peculiar language characteristics and eating habits. Thus, these adjustments resulted in the revised Brazilian version of DKN-A [13], which was used in the present study.

The DSCAQ [19] [21] assesses levels of self-care in different aspects of DM treatment, not adherence to the prescribed regimen, as there is no specific, unchanging "gold standard" to which one's behavior should be compared. In addition, the DSCAQ distinctly assesses each self-care behavior because these behaviors do not have strong correlations with each other [19] [21]. It has the following dimensions: general diet, specific diet, physical activity, blood glucose monitoring, foot care, and medication. Performance in each dimension is measured by the average number of days of the week the respondent performs the behavior. There are three other items related to smoking (if you smoked during the last seven days; how many cigarettes do you usually smoke in a day; and when did you last smoke). Permission from authors of the Brazilian version to use this instrument was obtained in previous studies [9] [10].

\subsection{Study Interventions}

The EP was developed individually, in a private room on the premises of the study site, by scheduling by mutual agreement and through nursing consultations with trained professionals (nurses). The frequency of the meetings was according to the individual needs of each participant regarding the topics addressed, conducted face to face and dialogically, with a collaborative approach, average duration of 50 minutes and a maximum of 30 days. Illustrative posters, prepared by the researchers themselves, containing public domain images related to the general management of the disease and self-care were used. The educational material was based on the literature and included the following topics: description of the disease process and treatment modalities; practice of 
physical activity integrated with lifestyle; blood glucose monitoring and interpretation; body weight control; proper use of medicines; and prevention of complications [16] [17].

The EP also included 42 physical training sessions, for which the concurrent training methodology, characterized by aerobic exercise in combination with anaerobic or resistance exercise, was adopted. The aerobic exercises consisted of three weekly sessions of elliptical, treadmill and bicycle, lasting 30 minutes. Resistance exercises were applied to the upper and lower limbs, with three sets of 12 repetitions, also in three weekly sessions lasting 30 minutes. All exercise sessions were performed in a properly equipped gym, on the premises of the study site, and with the direct supervision of physical education professionals. It is noteworthy that the individual educational meetings took place in parallel with the concurrent physical training sessions, which were developed in small groups of three to five people over a period of six months [16] [17].

\subsection{Statistical Analysis}

The collected data were double-typed in the MS-Excel application and then processed electronically for validation. The data sheet was later exported to SPSS version 17.0 software. Sociodemographic, clinical and treatment variables were submitted to descriptive statistics, and the results were expressed as mean and standard deviation, or in absolute and relative frequencies.

For comparisons between two dependent samples (knowledge assessment and self-care before and after the development of EP with physical training), the Wilcoxon-Mann-Whitney test was used, since the normal distribution was not evident. The significance level (p) adopted was less than 0.05 .

\section{Results}

\subsection{Sociodemographic, Clinical and Treatment Characterization of the Sample}

The sample studied consisted of $78.8 \%$ female; mean age 60.2 years (standard deviation - SD = 11.5); $60.6 \%$ were married; average schooling time of 6.4 years $(\mathrm{SD}=5.2)$; average monthly household income of 2093 reais ( $\$ 508 \mathrm{USD})$ ( $\mathrm{SD}=$ 1670; \$405 USD); mean time since diagnosis was 8.5 years ( $\mathrm{SD}=7.8$ ); using oral antidiabetic drugs as a prescribed drug treatment (78.8\%); and lack of prior participation in diabetes orientation groups (100\%).

\subsection{Knowledge about the Disease and Self-Care Activities with DM}

The knowledge evaluation showed statistically significant differences between the two moments of the study, indicating an improvement in the participants' level of knowledge after the educational program. Regarding self-care, from the clinical point of view, there was an improvement in the performance of all activities; however, only the dimension "general diet" obtained a statistically signifi- 
cant improvement. Mean values and standard deviations, and comparisons between times (T0 and T6) are shown in Table 1.

The DSCAQ items related to smoking did not change, since all participants had never smoked, and this behavior remained until the end of the study.

\section{Discussion}

In general, the sociodemographic, clinical and treatment characterization resembled that of other Brazilian population samples of people with DM [8] [22] [23] [24] [25].

The predominance of women can be attributed to both their higher demand and/or use of health services [26] [27], as well as the increased prevalence of DM in the Brazilian female population [28]. This last condition may be related to population aging and, in Brazil, there is a significant contingent of elderly women, especially in the older age groups, where the involvement by chronic diseases tends to be higher [29].

Low education requires adaptations in the teaching-learning process [22] [30] and, for this reason, it is believed that the EP modality proposed in this study, conducted in order to meet to the individual needs of each participant, contributed to a better understanding of the disease and its management. Another important aspect to be considered is the fact that the educational meetings were developed individually, not in groups. Some educational intervention studies conducted among Brazilian adults with DM have shown that the group modality is more advantageous than the individual [24] [31]. However, it is reiterated that for the present study, the individual face-to-face mode, in a collaborative approach, was more viable because it allowed closer contact between professionals and participants, and the latter could consolidate their knowledge and clarify the their doubts, each at its own pace, without the need to "accompany a group"

Table 1. Comparison of the means, between time, knowledge about the disease and self-care in the sample studied. Guaxupé, Minas Gerais, Brazil, 2019.

\begin{tabular}{|c|c|c|c|}
\hline Variables & $\begin{array}{c}\text { Before } \mathrm{EP}^{*}(\mathrm{~T} 0) \\
\text { Average }\left(\mathrm{SD}^{* *}\right) \\
\mathrm{n}=\mathbf{3 3}\end{array}$ & $\begin{array}{c}\text { After } \mathrm{EP}^{*}(\mathrm{~T} 6) \\
\text { Average }\left(\mathrm{SD}^{* *}\right) \\
\mathrm{n}=18\end{array}$ & p-value \\
\hline Knowledge about Diabetes (DKN-A) & $9.2(2.8)$ & $13.5(1.3)$ & $0.000^{* * *}$ \\
\hline \multicolumn{4}{|l|}{$\begin{array}{l}\text { Diabetes Self-Care Activity Questionnaire } \\
\text { (DSCAQ) }\end{array}$} \\
\hline General food & $2.1(1.8)$ & $3.8(3.0)$ & $0.022^{* * *}$ \\
\hline Specific Food & $4.7(1.3)$ & $5.3(1.0)$ & 0.064 \\
\hline Physical activity & $4.7(1.3)$ & $5.6(2.0)$ & 0.232 \\
\hline Blood glucose monitoring & $1.6(2.5)$ & $2.0(2.6)$ & 0.261 \\
\hline Foot Care & $3.3(1.8)$ & $4.2(1.5)$ & 0.151 \\
\hline Medication & $4.4(1.5)$ & $5.0(1.7)$ & 0.067 \\
\hline
\end{tabular}

${ }^{\star}$ EP: Education Program; ${ }^{* * S D}$ : standard-deviation; ${ }^{* * *}$ Statistical significance $(\mathrm{p}<0.05)$. 
[16]. This strategy strengthens the sense of autonomy and empowerment, especially of older individuals [32], as is the case with most participants in this study.

In the study group, the average time of diagnosis was less than 10 years, considered a facilitating factor for adherence to EP. The recent experience with the disease and its treatment may be the motivation to develop skills and behaviors directed to its control [33] [34]. On the other hand, it is known that a longer time of disease predisposes to the emergence of complications, which can become obstacles to the participation in educational activities and, consequently, to access to information essential to self-care [22] [35].

The fact that the entire sample referred to previous non-participation in educational activities about DM suggests a devaluation of people in relation to this type of activity, and even a difficulty in assuming their own treatment, as well as the lack of incentive or appreciation by health services. Both situations can be a barrier to behavioral change. However, the development of the present study may have met this demand from people [16] and yet, 15 (45.4\%) participants dropped out during the research.

It is widely recognized that DM education is an integral part of disease management [5] [36] [37], however, its realization becomes a challenge in the context of Brazilian health system, which is still based on prescriptive and curative actions [38]. Moreover, it depends on the availability of professionals familiar with the educational techniques [5] [39] and, especially, on people's willingness and interest [40], once that those with less education do not seem to value preventive actions, such as health education [39].

It is noteworthy that the proposed EP included 42 concurrent physical training sessions, providing free access to equipment and direct supervision of physical educators, as well as allowing peer interaction in small groups. This seems to have been a motivating factor for more than half of the participants to remain in follow-up in the study [16]. A qualitative study, conducted among long-lived elderly women in Florianópolis-SC, Brazil, on barriers and facilitators for physical activity practice, showed that physical exercise appropriate to clinical conditions and the perception of its benefits in terms of health and quality of life, as well as peer company and professional accompaniment, were fundamental for adherence to this self-care behavior [41].

Regarding drug treatment, the use of OADs by most participants is consistent with the average time of diagnosis (less than 10 years). Other studies developed in Brazilian samples of adults and elderly with T2DM, for which the mean time of disease was up to 10 years, the drug therapy resembles that found in this research [23] [24] [31].

Regarding knowledge about DM, a statistically significant improvement was observed after EP $(p=0.000)$. It is noteworthy that even before the educational interventions, the group studied presented a satisfactory level of general knowledge (average score above eight points), a result that was not expected due to the fact that no patient had previously participated in DM education groups, be- 
cause of advanced age and low education, and also because the time of diagnosis is relatively short. A systematic review of educational practices for diabetic patients and health professionals' perspective showed that advanced age did not represent learning difficulties, as well as the level of functional health literacy, an aspect that is still little explored in the Brazilian population [5]. However, as discussed earlier, poor experience with the disease may have been the motivating factor for seeking knowledge in order to engage in behaviors appropriate to its control [34]. It should also be considered that the advancement of technology has enabled access to resources and information sources such as the Internet, favoring the acquisition of greater knowledge.

A study with the same methodological design as the present study, developed in a sample of 82 adults with T2DM in São Paulo State, Brazil, whose follow-up time was 12 months and educational interventions carried out with the aid of the "Diabetes Conversation Maps" tool, improved significant in knowledge about the disease $(\mathrm{p}<0.001)$, which was also assessed using the DKN-A instrument [13].

Another study of educational intervention carried out in the interior of São Paulo State, Brazil, in a sample of 64 adults with T2DM subdivided into two groups $(\mathrm{n}=32)$ followed for six months, with the objective of evaluating knowledge about the disease through the DKN-A instrument showed significant improvement of knowledge in the experimental group compared to the control group [42].

A randomized clinical trial conducted at a referral outpatient clinic for hypertension in the state of Goiás, Brazil, in a sample of 76 hypertensive patients with DM followed for six months, and whose intervention group participated in educational activities based on the problematic methodology, also identified improved knowledge about DM at the end of interventions $(\mathrm{p}=0.000)$, although this variable was evaluated using another instrument [43].

More recently, a randomized controlled trial conducted in a municipality in southern Brazil, involving 134 adults with T2DM allocated to two groups ( $\mathrm{n}=$ 67), aimed to verify the effects on knowledge and attitude towards the disease, quality and quality of life of life and adherence to self-care activities of nursing consultations based on the supported self-care methodology. Both groups received the usual care from the basic health unit in which they were registered, and the intervention group also received nursing appointments interspersed by telephone monitoring during the 10-month period. It was found that the intervention group had significantly higher level of knowledge about DM $(\mathrm{p}<0.001)$ than the control group, assessed by the DKN-A instrument at the end of the study [44].

The studies cited corroborate the present research, showing that educational programs developed with lightweight, low cost and simple execution technology [43] are effective to improve the knowledge about the disease among people with DM and should be incorporated into health services, both for those who provide 
formal care (units of the Brazilian Nacional Health System) and those who provide informal care, as is the case of the present study. Although the heterogeneity of educational strategies among research contributes to the lack of a gold standard model of DM education, the findings reinforce that cognitive changes (knowledge) are more sensitive to educational interventions than behavioral changes (self-care) independently of the educational modality. As knowledge is considered a predictor of self-care behaviors, its improvement may positively influence such behaviors [45].

Regarding self-care with DM, the studied sample showed clinical improvement in all dimensions, but only the dimension "general diet" showed a statistically significant difference $(\mathrm{p}=0.022)$. It refers to following a balanced diet through professional guidance. The dietary guidelines developed in the proposed EP seem to have contributed to improve adherence to this therapeutic component, and are in line with the literature recommendations that the initial emphasis of dietary treatment should be the adequacy of nutrient intake. Later, one should stick to more specific aspects related directly to glycemic control [46]. This may be an explanation for better adherence to the "general diet" dimension than to "specific diet" since the latter covers dietary restrictions, and this behavior is more difficult to perform [47]. A cross-sectional study of a quantitative approach, developed in an outpatient service of a city in Pernambuco, Brazil, with the objective of describing the self-care activities of 164 diabetic users, through the DSCAQ instrument, also revealed better performance in the "general diet" dimension of the patient than in the "specific diet" dimension [22].

A quasi-experimental 12-month follow-up study of 127 patients with T2DM who participated in an educational program for empowerment in self-care practices in five outpatient units in a city in the state of Minas Gerais, Brazil, which aimed to evaluate the effect of this program in meeting self-care goals showed that diet was the main target in changing patients' behavior, especially regarding fiber frequency, quantity and inclusion [31], corroborating the present study.

For the dimension "physical activity", the absence of statistical significance can be attributed to the fact that, before the beginning of the EP, more than half of the initial sample already practiced some type of activity. This finding is interesting because studies with Brazilian population samples of diabetic adults with different designs using the same or similar instrument show low adherence to physical activity [10] [22] [44], contrary to the present investigation.

Regarding the dimension "blood glucose monitoring", it is important to emphasize that most participants in this study use oral antidiabetic drugs as a prescribed drug treatment and this constitutes a "exclusion criterion" for free access by the Brazilian National Health System, the glucometer and other inputs for the evaluation of capillary blood glucose at home, as provided by Federal Law No. $11,347 / 2006$ [48] and Ordinance No. 2583/2007 [49]. It is stated by the latter that, for DM users in oral therapy, capillary glycemia can be performed at the health unit itself during regular assessment visits defined by the team, according 
to the established protocol. It is also important to highlight that the handling of the glucometer and other inputs requires the development of technical skills, which can be complex for people with low education, such as the sample studied. An integrative review study on self-monitoring of home blood glucose revealed that because of socioeconomic (cost of tapes and/or lancets) or psychological (fear of needles, finger puncture, or inability to handle glucometer) issues, many patients do not perform this test procedure [50].

Similarly, the dimension "foot care" was not statistically significant. It is believed that the short intervention time may not have been sufficient to consolidate the skills necessary for self-monitoring of blood glucose and self-care with the feet, as well as the fact that the studied sample consisted mostly of elderly people which may have some difficulty or functional limitation to perform these behaviors.

Contrary to the present investigation, an experimental study conducted in health centers in the city of San Luis Potosí, Mexico, with the main objective of evaluating foot care habits before, at the end and six months after an educational intervention based on participatory communication (intervention group: $\mathrm{n}=77$ ) and traditional communication (control group: $n=77$ ), whose participants were, on average, 52 years old, showed better results in the intervention group ( $\mathrm{p}$ $<0.001$ ) between the first and second second assessment [51]. Another quasi-experimental study, conducted in two outpatient services of a municipality in the state of Piauí, Brazil, in a total sample of 55 adults with T2DM and a mean age of 59 years, aimed to evaluate the effect of an educational intervention. When adhering to self-care activities, through the DSCAQ instrument, it was shown that the item with the best adherence was "to examine inside the shoes before putting them on", within the "foot care" dimension [25]. In this study, advanced age and small sample size may have contributed to the absence of statistical significance in this dimension.

Finally, the "medication" dimension similarly showed no statistically significant difference, showing that medication adherence was already satisfactory even before the start of the proposed EP. This result corroborates with other national studies developed with different designs, but with the same self-care assessment tool [10] [22] [52]. The study conducted in the state of Piauí, Brazil, mentioned earlier [25], showed a low adherence to the item "taking insulin injections as recommended", within the "medication" dimension. Adherence to DM drug treatment varies widely in the literature, which reinforces the need for further research on this topic.

The results of the present study show, therefore, a significant improvement of knowledge about the disease and its treatment, which was not equally observed for most self-care activities with DM. Although changes in knowledge are necessary for behavioral changes, having proper knowledge of the disease does not mean acquiring new habits [6] [53]. Modifying behaviors is a process that requires time, motivation and regular reinforcement, and there is a consensus in 
the literature that health education is the only strategy that can bring all these elements together and, therefore, should be implemented for people with DM for effective control of the disease [44].

Some limitations of this study deserve to be pointed out, such as: lack of control group and small sample size, which limit the establishment of evidence about the proposed intervention; and individuals who completed the study could be those who were most motivated and proactive in finding resources to control DM.

\section{Conclusions}

The sample presented a sociodemographic and clinical profile similar to other Brazilian population samples that have the disease. Advanced age, low education and family income, and short time of diagnosis may be factors that hinder the performance of some self-care activities, due to the little experience these people have in managing their condition.

The proposed EP proved to be beneficial for improving knowledge and self-care with the disease, although for this last variable, the improvement was only from the clinical point of view. These findings reiterate the need to maintain interventions of this nature and the importance of greater investments in issues related to self-care during the development of educational programs for people with diabetes mellitus.

\section{Conflicts of Interest}

The authors declare no conflicts of interest regarding the publication of this paper.

\section{References}

[1] Sociedade Brasileira de Diabetes (2017) Diretrizes da Sociedade Brasileira de Diabetes 2017-2018. Clannad, São Paulo.

[2] Iser, B.P.M., Stopa, S.R., Chueiri, P.S., Szwarcwald, C.L., Malta, D.C., Monteiro, H.O.C., Duncan, B.B. and Schmidt, M.I. (2015) Self-Reported Diabetes Prevalence in Brazil: Results from National Health Survey 2013. Epidemiologia \& Serviços de Saúde, 24, 305-314. https://doi.org/10.5123/S1679-49742015000200013

[3] IDF (2019) IDF Diabetes Atlas. The International Diabetes Federation, Brussels.

[4] Grillo, M.F.F., Neumann, C.R., Scain, H.S., Rozeno, R.F., Gross, J.L. and Leitão, C.B. (2013) Effect of Different Types of Self-Management Education in Patients with Diabetes. Revista da Associação Médica Brasileira, 59, 400-405. https://doi.org/10.1016/j.ramb.2013.02.006

[5] Iquize, R.C.C., Theodoro, F.C.E.T., Carvalho, K.A., Oliveira, M.A., Barros, J.F. and Silva, A.R. (2017) Educational Practices in Diabetic Patient and Perspective of Health Professional: A Systematic Review. Jornal Brasileiro de Nefrologia, 39, 196-204. https://doi.org/10.5935/0101-2800.20170034

[6] Strömberg, A. (2005) The Crucial Role of Patient Education in Heart Failure. The European Journal of Heart Failure, 7, 363-369. https://doi.org/10.1016/j.ejheart.2005.01.002 
[7] Cazarini, R.P., Zanetti, M.L., Ribeiro, K.P., Pace, A.E. and Foss, M.C. (2002) Adherence of People with Diabetes Mellitus to an Educational Group: Percentage and Causes. Medicina, 35, 142-150. https://doi.org/10.11606/issn.2176-7262.v35i2p142-150

[8] Moreschi, C., Rempeli, C., Siqueira, D.F., Backes, D.S., Pissaia, L.F. and Grave, M.T.Q. (2018) Family Health Strategies: Profile/Quality of Life of People with Diabetes. Revista Brasileira de Enfermagem, 71, 3073-3080. https://doi.org/10.1590/0034-7167-2018-0037

[9] Gomides, D.S., Gomes-Villas Boas, L.C., Coelho, A.C.M. and Pace, A.E. (2013) Self-Care of People with Diabetes Mellitus Who Have Lower Limb Complications. Acta Paulista de Enfermagem, 26, 289-293. https://doi.org/10.1590/S0103-21002013000300014

[10] Coelho, A.C.M., Gomes-Villas Boas, L.C., Gomides, D.S., Foss-Freitas, M.C. and Pace, A.E. (2015) Self-Care Activities and Their Relationship to Metabolic and Clinical Control of People with Diabetes Mellitus. Texto \& Contexto Enfermagem, 24, 697-705. https://doi.org/10.1590/0104-07072015000660014

[11] Rodrigues, F.F.L., Zanetti, M.L., Santos, M.A., Martins, T.A., Sousa, V.D. and Teixeira, C.R.S. (2009) Knowledge and Attitude: Important Components in Diabetes Education. Revista Latino-Americana de Enfermagem, 17, 468-473. https://doi.org/10.1590/S0104-11692009000400006

[12] Torres, H.C., Franco, L.J., Stradioto, M.A., Hortale, V.A. and Schall, V.T. (2009) Evaluation of Group and Individual Strategies in a Diabetes Education Program. Revista de Saúde Pública, 43, 291-298. https://doi.org/10.1590/S0034-89102009005000001

[13] Figueira, A.L.G., Gomes-Villas Boas, L.C., Coelho, A.C.M., Foss-Freitas, M.C. and Pace, A.E. (2017) Educational Interventions for Knowledge on the Disease, Treatment Adherence and Control of Diabetes Mellitus. Revista Latino-Americana de Enfermagem, 25, e2863. https://doi.org/10.1590/1518-8345.1648.2863

[14] Vieira, G.L.C., Cecílio, S.G. and Torres, H.C. (2017) The Perception of Users with Diabetes Regarding a Group Education Strategy for the Promotion of Self-Care. Revista da Escola de Enfermagem Anna Nery, 21, e0017. https://doi.org/10.5935/1414-8145.20170017

[15] Polit, D.F. and Beck, C.T. (2011) Fundamentos de pesquisa em enfermagem: Avaliação de evidências para a prática da enfermagem. Artmed, Porto Alegre.

[16] Silva Júnior, A.J. and Gomes, L.C. (2019) Effects of an Educational Program Focused on Self-Care and Concurrent Physical Training on Glycemia and Drug Treatment of Patients with Diabetes Mellitus. Diabetes Updates, 5, 1-7. https://doi.org/10.15761/DU.1000116

[17] Silva Júnior, A.J., Brito, F.I. and Gomes, L.C. (2019) Cardiovascular Parameters of People with Diabetes Mellitus: An Intervention Study. Current Research in Diabetes \& Obesity Journal, 10, 1-6.

[18] Dunn, S.M., Bryson, J.M., Hoskins, P.L., Alford, J.B., Handelsman, D.J. and Turtle, J.R. (1984) Development of the Diabetes Knowledge (DKN) Scales: Forms DKN-A, DKN-B, and DKN-C. Diabetes Care, 7, 36-41. https://doi.org/10.2337/diacare.7.1.36

[19] Toobert, D.J., Hampson, S.E. and Glasgow, R.E. (2000) The Summary of Diabetes Self-Care Activities Measure: Results from 7 Studies and a Revised Scale. Diabetes Care, 23, 943-950. https://doi.org/10.2337/diacare.23.7.943

[20] Torres, H.C., Hortale, V.A. and Schall, V.T. (2005) Validation of Diabetes Mellitus Knowledge (DKN-A) and Attitude (ATT-19) Questionnaires. Revista de Saúde 
Pública, 39, 906-911. https://doi.org/10.1590/S0034-89102005000600006

[21] Michels, M.J., Coral, M.H.C., Sakae, T.M., Damas, T.B. and Furnaletto, L.M. (2010) Questionnaire of Diabetes Self-Care Activities: Translation, Cross-Cultural Adaptation and Evaluation of Psychometric Properties. Arquivos Brasileiros de Endocrinologia e Metabologia, 54, 644-651. https://doi.org/10.1590/S0004-27302010000700009

[22] Santos, E.M., Souza, V.P., Correio, I.A.G. and Correio, E.S.B. (2018) The Self-Care of Users Bearing Diabetes Mellitus: Socio-Demographic, Clinical and Therapeutic Profiles. Revista Online de Pesquisa: Cuidado é Fundamental, 10, 720-728. https://doi.org/10.9789/2175-5361.2018.v10i3.720-728

[23] Piza, L.F., Eleotério, B.D. and Gomes, L.C. (2018) Evaluation of the Feet of Elderly People with Diabetes Mellitus: Descriptive Study. Enfermagem Brasil, 17, 245-252. https://doi.org/10.33233/eb.v17i3.1097

[24] Marques, M.B., Coutinho, J.F.V., Martins, M.C., Lopes, M.V.O., Maia, J.C. and Silva, M.J. (2019) Educational Intervention to Promote Self-Care in Older Adults with Diabetes Mellitus. Journal of School of Nursing-Univesity of São Paulo, 53, e03517. https://doi.org/10.1590/s1980-220x2018026703517

[25] Moura, N.S., Lopes, B.B., Teixeira, J.J.D., Oriá, M.O.B., Vieira, N.F.C. and Guedes, M.V.C. (2019) Literacy in Health and Self-Care in People with Type 2 Diabetes Mellitus. Revista Brasileira de Enfermagem, 72, 734-740. https://doi.org/10.1590/0034-7167-2018-0291

[26] Levorato, C.D., Mello, L.M., Silva, A.S. and Nunes, A.A. (2014) Factors Associated with the Demand for Health Services from a Gender-Relational Perspective. Ciência \& Saúde Coletiva, 19, 1263-1274. https://doi.org/10.1590/1413-81232014194.01242013

[27] Botton, A., Cúnico, S.D. and Strey, M.N. (2017) Gender Differences in the Access to Health Services: Necessary Problematization. Mudanças-Psicologia da Saúde, 25, 67-72. https://doi.org/10.15603/2176-1019/mud.v25n1p67-72

[28] Flor, L.S. and Campos, M.R. (2017) The Prevalence of Diabetes Mellitus and Its Associated Factors in the Brazilian Adult Population: Evidence from a Population-Based Survey. Revista Brasileira de Epidemiologia, 20, 16-29. https://doi.org/10.1590/1980-5497201700010002

[29] Pimenta, F.B., Pinho, L., Silveira, M.F. and Botelho, A.C.C. (2015) Factors Associated with Chronic Diseases among the Elderly Receiving Treatment under the Family Health Strategy. Ciência \& Saúde Coletiva, 20, 2489-2498. https://doi.org/10.1590/1413-81232015208.11742014

[30] Nicolato, F.V., Couto, A.M. and Castro, E.A.B. (2016) Capacity for Self-Care of Elderly People Attended in Nursing Consultation in Secondary Health Care. Revista de Enfermagem do Centro Oeste Mineiro, 6, 2199-2211. https://doi.org/10.19175/recom.v6i2.1016

[31] Cortez, D.N., Santos, J.C., Macedo, M.M.L., Souza, D.A.S., Reis, I.A. and Torres, H.C. (2018) Effects of an Educational Program on Self-Care Empowerment for the Fulfillment of Goals in Diabetes. Ciencia y Enfermería, 24, 23-32.

[32] Mendes, G.F., Rezende, A.L.G., Dullius, J. and Nogueira, J.A.D. (2017) Adherence Barriers and Facilitators to a Diabetes Education Program: The User's Point of View. Brazilian Journal of Physical Activity and Health, 22, 278-289. https://doi.org/10.12820/rbafs.v.22n3p278-289

[33] WHO (2003) Adherence to Long-Term Therapies: Evidence for Action. The World Health Organization, Geneva. 
[34] Gimenes, H.T., Zanetti, M.L. and Haas, V.J. (2009) Factors Related to Patient Adherence to Antidiabetic Drug Therapy. Revista Latino-Americana de Enfermagem, 17, 46-51. https://doi.org/10.1590/S0104-11692009000100008

[35] Cortez, D.N., Reis, I.A., Souza, D.A.S., Macedo, M.M.L. and Torres, H.C. (2015) Complications and the Time of Diagnosis of Diabetes Mellitus in Primary Care. Acta Paulista de Enfermagem, 28, 250-255. https://doi.org/10.1590/1982-0194201500042

[36] Funnell, M., Brown, T.L., Childs, B.P., Haas, L.B., Hosey, G.M., Jensen, B., Maryniuk, M., Peyrot, M., Piette, J.D., Reader, D., Siminerio, L.M., Weinger, K. and Weiss, M.A. (2010) National Standards for Diabetes Self-Management Education. Diabetes Care, 33, S89-S96. https://doi.org/10.2337/dc10-S089

[37] Amorim, M.M.A., Ramos, N., Bento, I.C. and Gazzinelli, M.F. (2013) Educational Intervention in Diabetes Mellitus. Psicologia, Saúde \& Doenças, 14, 168-184. https://doi.org/10.15309/13psd140111

[38] Malta, D.C. and Merhy, E.E. (2010) The Path of the Line of Care from the Perspective of Nontransmissible Chronic Diseases. Interface: Comunicação, Saúde, Educação, 14, 593-606. https://doi.org/10.1590/S1414-32832010005000010

[39] Pace, A.E., Ochoa-Vigo, K., Caliri, M.H.L. and Fernandes, A.P.M. (2006) Knowledge on Diabetes Mellitus in the Self Care Process. Revista Latino-Americana de Enfermagem, 14, 728-734. https://doi.org/10.1590/S0104-11692006000500014

[40] Pereira, F.R.L., Torres, H.C., Cândido, N.A. and Alexandre, L.R. (2009) Promoting Self-Care in Diabetes Mellitus Individually and in Group Work. Ciência, Cuidado \& Saúde, 8, 594-599. https://doi.org/10.4025/cienccuidsaude.v8i4.9686

[41] Krug, R.R., Lopes, M.A. and Mazo, G.Z. (2015) Barriers and Facilitators for the Practice of Physical Activity in Old and Physically Inactive Women. Revista Brasileira de Medicina do Esporte, 21, 57-64. https://doi.org/10.1590/1517-86922015210101673

[42] Barbosa, L., Borges, P.C.P., Lemos, S.S. and Cesarino, C.B. (2016) Evaluation of Group Educational Intervention for Diabetics Receiving Care at Teaching Clinic. Revista de Enfermagem da UERJ, 24, e4968.

[43] Pereira, D.A., Costa, N.M.S.C., Sousa, A.L.L., Jardim, P.C.B.V. and Zanini, C.R.O. (2012) The Effect of Educational Intervention on the Disease Knowledge of Diabetes Mellitus Patients. Revista Latino-Americana de Enfermagem, 20, 478-485. https://doi.org/10.1590/S0104-11692012000300008

[44] Teston, E.F., Peternella, F.M.N., Sales, C.A., Haddad, M.C.L., Cubas, M.R. and Marcon, S.S. (2018) Effect of the Consultation of Nursing on Knowledge, Quality of Life, Attitude towards Disease and Self-Care among Persons with Diabetes. Revista Mineira de Enfermagem, 22, e-1106. https://doi.org/10.5935/1415-2762.20180034

[45] Cardoso, A.F., Queirós, P. and Ribeiro, C.F. (2015) Therapeutic Self-Care Management Interventions for Individuals with Diabetes Mellitus: Systematic Review. Revista Portuguesa de Saúde Pública, 33, 246-255. https://doi.org/10.1016/j.rpsp.2015.04.001

[46] Lottenberg, A.M.P. (2008) Diet Composition along the Evolution of Type 1 Diabetes Mellitus. Arquivos Brasileiros de Endrocrinologia e Metabologia, 52, 250-259. https://doi.org/10.1590/S0004-27302008000200012

[47] Péres, D.S., Santos, M.A., Zanetti, M.L. and Ferronato, A.A. (2007) Dificuldades dos pacientes diabéticos para o controle da doença: Sentimentos e comportamentos. Revista Latino-Americana de Enfermagem, 15, 1105-1112. https://doi.org/10.1590/S0104-11692007000600008 
[48] Law No. 11,347 of September 27, 2006 (2006) It Provides Free Distribution of Medicines and Materials Necessary for Its Application and Monitoring of Blood Glucose to Diabetes Patients Enrolled in Diabetes Education Programs. Official Gazette, Brasilia.

[49] Ordinance No. 2,583 (2007) Defines the List of Medicines and Supplies Made Available by the Unified Health System, Pursuant to Law No. 11.347, 2006, to Users with Diabetes Mellitus. Official Gazette, Brasilia.

[50] Teixeira, C.R.S., Zanetti, M.L., Landim, C.A.P., Becker, T.A.C., Santos, E.C.B., Franco, R.C. and Citro, R. (2009) Self-Monitoring Blood Glucose at Home: Integrative Literature Review. Revista Eletrônica de Enfermagem, 11, 1006-1017. https://doi.org/10.5216/ree.v11i4.33257

[51] Rodríguez, M.C.P., Godoy, S., Mazzo, A., Nogueira, P.C., Trevizan, M.A. and Mendes, I.A.C. (2013) Diabetic Foot Care before and after an Educative Intervention. Enfermería Global, 12, 53-62.

[52] Souza, J.D., Baptista, M.H.B., Gomides, D.S. and Pace, A.E. (2017) Adherence to Diabetes Mellitus Care at Three Levels of Health Care. Escola Anna Nery-Revista de Enfermagem, 21, e20170045. https://doi.org/10.1590/2177-9465-ean-2017-0045

[53] Knight, K.M., Dornan, T. and Bundy, C. (2006) The Diabetes Educator: Trying Hard, But Must Concentrate More on Behavior. Diabetic Medicine, 23, 485-501. https://doi.org/10.1111/j.1464-5491.2005.01802.x 